\title{
Impulsiveness in pigeons living in the experimental chamber
}

\author{
A. W. LOGUE, ADOLFO CHAVARRO, H. RACHLIN, and R. W. REEDER \\ State University of New York at Stony Brook, Stony Brook, New York
}

\begin{abstract}
Pigeons' choices between larger, more delayed and smaller, less delayed reinforcers were examined while the pigeons lived in the experimental chamber for 23-h sessions. In Condition 1 , 4 pigeons were food deprived prior to each session and exposed to one session every 4 th day. Condition 2 was identical except that the pigeons began each session at their ad-lib weights. Condition 3 was identical to Condition 2 except that sessions were conducted on consecutive days. Con dition 4 was identical to Condition 3 except that the subjects ( 2 pigeons from Conditions $1-3$ plus a naive pigeon) could obtain reinforcers much less frequently. In all of the conditions, the pigeons consistently chose the smaller, less delayed reinforcers; the pigeons were impulsive. The restriction of food access caused a disruption in the diurnal pattern of feeding, but did not decrease impulsiveness even in this 23 -h live-in procedure.
\end{abstract}

Significant research effort has been devoted to the question of whether nonhuman subjects choose adaptively among different foods (see, e.g., Commons, Herrnstein, \& Rachlin, 1982; Kamil \& Sargent, 1981; Staddon, 1980 ). One such research area concerns pigeons' choices between varying durations and delays of access to food. If a pigeon chooses longer but more delayed access to food over shorter but less delayed access to food, that pigeon's behavior is termed self-control; the opposite choice is termed impulsiveness (Ainslie, 1974; Grosch \& Neuringer, 1981; Rachlin \& Green, 1972). It has been argued that, given that both types of reinforcers occur with the same frequency, self-control is adaptive but impulsiveness is not, because self-control maximizes total food consumed (Collier, 1982, 1983). Nevertheless, it has been very difficult to demonstrate self-control in pigeons. Pigeons show self-control only if precommitment or special training procedures are used, and only when specific events occur during the reinforcer delays (Ainslie, 1974; Grosch \& Neuringer, 1981; Logue \& Mazur, 1981; Logue \& Peña-Correal, 1984; Logue, Rodriguez, PeñaCorreal, \& Mauro, 1984; Mazur \& Logue, 1978; Rachlin \& Green, 1972).

Two explanations have been offered for this apparent nonadaptiveness in pigeons' behavior. One possibility is that the pigeons behave nonadaptively and are impulsive because they are tested in an unnatural situation. For example, the experiments usually consist of short sessions with experimenter-controlled brief repeated access to food, and the pigeons are extremely food deprived at the start of a session (usually to $80 \%$ of their free-feeding

This research was supported by grants from the National Science Foundation. Some of these data were presented at the Annual Meeting of the Eastern Psychological Association, Arlington, Virginia, 1986. Requests for reprints should be sent to A. W. Logue, Department of Psychology, State University of New York at Stony Brook, Stony Brook, NY 11794. weights). When an animal is extremely food deprived, it may not be adaptive for that animal to wait for larger amounts of food when smaller amounts are available sooner. Furthermore, pigeons may not demonstrate adaptive changes in their feeding behavior unless they are exposed to relatively long sessions containing multiple meals presented under their control (Collier, 1982, 1983; Collier, Hirsch, \& Kanarek, 1977; Collier, Johnson, Hill, \& Kaufman, 1986; Rachlin, Battalio, Kagel, \& Green, 1981; Rashotte, O'Connell, \& Beidler, 1982).

In addition, experiments on self-control typically employ an "open economy" (Collier, 1983; Hursh, 1980) in which the pigeons receive additional food outside of the experimental situation (the pigeons are fed as necessary following a session in order to maintain them at $80 \%$ of their free-feeding weights). There is therefore no incentive for the pigeon to make choices that would maximize the total received food within the experimental session; the pigeon's body weight will be kept the same regardless of its choices. Behavior can differ depending on whether the experimenter uses a "closed economy" (all food received within the experimental session: Collier, 1983; Hursh, 1980) or an open economy (see, e.g., Collier, 1982, 1983; Collier et al., 1986; Hursh, 1980; Peden \& Timberlake, 1984; Rashotte \& O'Connell, 1986).

Few of the procedures generally used in self-control experiments are characteristic of a natural environment (Rashotte et al., 1982), and, it has been argued, under more natural conditions pigeons would show better selfcontrol (Collier, 1982, 1983). This argument is similar to many others made within the past 15 years contending that operant conditioning experiments have not been sufficiently concerned with natural behavior (see, e.g., Bolles, 1985).

Alternatively, pigeons might be impulsive and behave nonadaptively in laboratory experiments because the 
pigeons are generally very sensitive to delays between their choices and the resulting reinforcers (prereinforcer delays), showing decreased preference for a reinforcer as these delays increase. Both pigeons and rats have been shown to choose less delayed over more delayed reinforcers, independently of whether or not these subjects are food-deprived, whether or not they are tested in an open economy, and even though their choices result in an explicit loss of total food received (for examples of such findings see Dunn \& Fantino, 1982; Hall-Johnson \& Poling, 1984; Hursh \& Fantino, 1973; Lea, 1979; Logan, 1965; Logue \& Peña-Correal, 1985; Logue, Smith, \& Rachlin, 1985; McDiarmid \& Rilling, 1965; Moore, 1979, 1982; Shull, Spear, \& Bryson, 1981; Timberlake, 1984). However, none of these experiments were performed using procedures in which the presentation of multiple meals was studied and in which the subject, rather than the experimenter, controlled the rate at which food was delivered. Therefore, it is still possible that pigeons might show self-control in a situation that contained more natural characteristics.

The present research explored this possibility by giving pigeons choices between longer, more delayed and shorter, less delayed access to food when the pigeons lived in the experimental chamber for $23-\mathrm{h}$ periods (for previous experiments in which pigeons lived in the experimental chamber, see Baum, 1972; Lucas, 1981; Rashotte, 1985; Rashotte \& O'Connell, 1986; Rashotte, Rautenberg, Henderson, \& Ostheim, 1986; Zeigler, Levitt, \& Levine, 1980). While the pigeons were in the chamber, more food was available than they could consume and the frequency with which food was received was usually controlled by the subject. All but one of the four experimental conditions involved no food deprivation. Because the pigeons were in the chamber for much longer periods of time than in previous experiments, there was a greater number of ways in which their behavior could vary in response to the contingencies in effect. For example, their choices might exhibit a diurnal rhythm. If the pigeons were still consistently impulsive within this situation, these results would provide strong evidence that pigeons' impulsiveness was due to sensitivity to reinforcer delay, and would eliminate several past unnatural characteristics of the testing procedure as causes.

\section{METHOD}

\section{Subjects}

Five adult White Carneau pigeons served as subjects. Pigeons $40,41,42$, and 43 served in Conditions 1-3. These pigeons had previously been used by Logue et al. (1985). The 5 th pigeon, Number 37, was experimentally naive and was added for Condition 4 because of the death of Pigeons 42 and 43 during the 8-month hiatus between Conditions 3 and 4 . During Condition 1 , while outside of the experimental chamber, the pigeons were weighed and fed between 8 and 9 a.m. each day in order to maintain them at $80 \%$ of their free-feeding weights. During Conditions 2-4, they had ad-lib access to food in their home cages. Water and grit were continuously available in the home cages for all of the conditions.
The home cages were kept in a room with a 12:12-h light:dark cycle, with light beginning at 7 a.m.

\section{Apparatus}

The experimental chamber was $33 \mathrm{~cm}$ long, $29 \mathrm{~cm}$ wide, and $31 \mathrm{~cm}$ high. Two response keys mounted on one wall, $21 \mathrm{~cm}$ above the floor and $15 \mathrm{~cm}$ apart, required a minimum force of $0.17 \mathrm{~N}$ to operate. The left key could be transilluminated with green light, and the right key with red light. A food hopper below the keys, the bottom edge of which was $7 \mathrm{~cm}$ above the floor of the chamber, provided access to mixed grain and grit when lit by two No. 1819 bulbs. The chamber could be illuminated by two $7.5-\mathrm{W}$ white lights, one 7.5-W green light, or one 7.5-W red light through a Plexiglas-covered hole in the aluminum ceiling. Water was continuously available from a cup located in the left corner of the wall opposite the keys. The chamber was enclosed in a sound-attenuating box. This box contained an air blower for ventilation that also helped to mask extraneous sounds. A Cromemco Z-2D computer in an adjacent room controlled the stimuli and recorded responses using a FORTRAN and Assembly program.

\section{Procedure}

Because of their prior experience, Pigeons 40, 41, 42, and 43 needed no preliminary training. Pigeon 37 was first trained to peck a key using an autoshaping procedure.

The basic procedure of the actual experiment was similar to that used by Logue et al. (1985). Each session lasted for $23 \mathrm{~h}$ and consisted of a series of discrete trials, most of which were choice trials. At the beginning of each choice trial, the left key was transillumi-

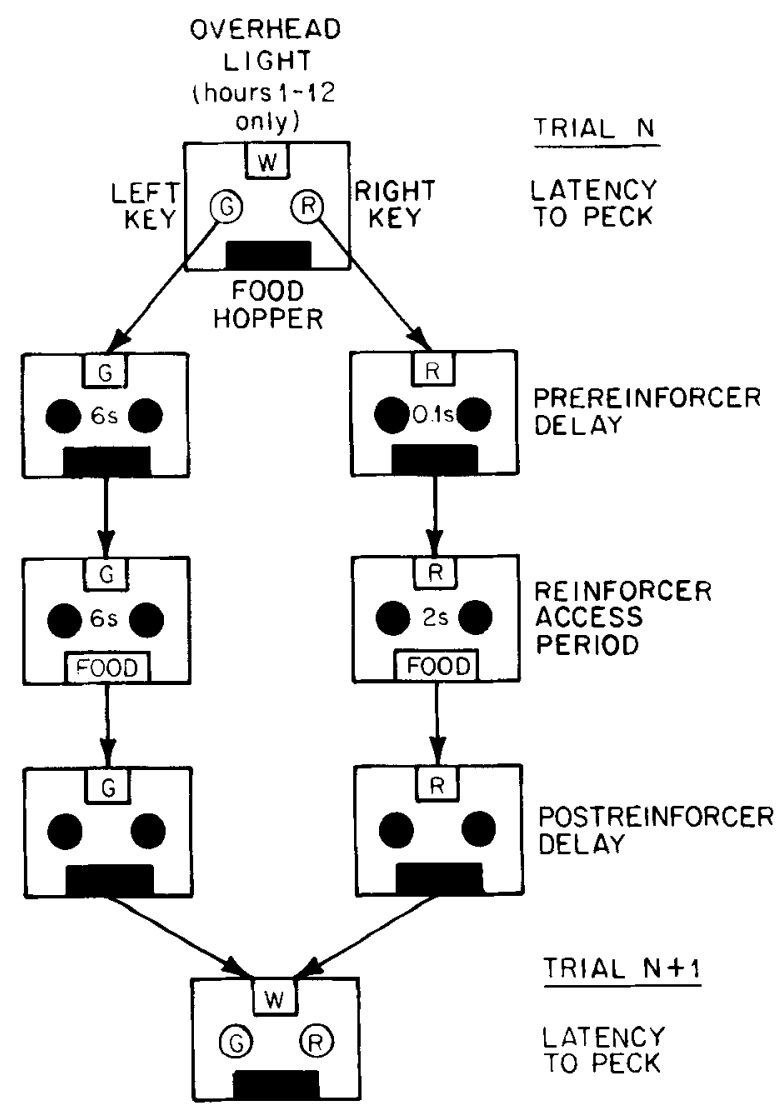

Figure 1. Diagram of the general procedure for a trial given a left (green) key peck or a right (red) key peck. The letters $W, G$, and $\mathbf{R}$ represent white, green, and red light, respectively. 
nated green and the right key was transilluminated red (see Figure 1). A single peck on either key produced a feedback click and turned both keys dark for the prereinforcer delay (the time between a response and access to reinforcement), which was followed by a period of access to mixed grain and grit (reinforcement), and then by the postreinforcer delay (the time between access to reinforcement and the start of the next trial; see below). After a green key peck, the chamber was illuminated with green light during the resulting prereinforcer delay $(6 \mathrm{sec})$, reinforcer access period $(6 \mathrm{sec})$, and postreinforcer delay. After a red key peck, the chamber was illuminated with red light during the resulting prereinforcer delay $(0.1 \mathrm{sec})$, reinforcer access period ( $2 \mathrm{sec})$, and postreinforcer delay. Thus, pecks on the left key were self-control choices, while pecks on the right key were impulsive choices. Pecks on dark keys had no effect. In addition to the occasional illumination of the chamber with red or green light as described above, to approximate the 12:12-h light:dark schedule present in the home cages, the chamber was illuminated with white light whenever the keylights were lit, but only during the first $12 \mathrm{~h}$ of each 23 -h session. Sessions began at 9 a.m.

Figure 2 diagrams the procedure for determining postreinforcer delays. With this procedure, as long as the pigeons responded fairly quickly, reinforcers were received at the rate of $1 / \mathrm{min}$ no matter which key was pecked. This was accomplished by (given a short response latency) having the postreinforcer delay last until $60 \mathrm{sec}$ (the programmed total trial time) had passed since the beginning of the current trial (the transillumination of the two key lights). With a long response latency, a period of reinforcer access might not end until after the 60-sec period (specifically, this occurred if the latency to peck was $48 \mathrm{sec}$ or more, so that the sum of the latency to peck, prereinforcer delay, and period of reinforcer access was at least $60 \mathrm{sec}$ ). In that case, following a left peck, the next trial began immediately after the end of the period of reinforcer access (i.e., the postreinforcer delay lasted $0 \mathrm{sec}$ ), and following a right peck, there was a fixed 9.9-sec postreinforcer delay before the next trial began. Thus, if the pigeons responded very slowly (with a latency of more than $48 \mathrm{sec}$ ), reinforcers would be received more slowly than $1 / \mathrm{min}$ but still at the same rate regardless of whether the left or the right key was pecked. For example, once the 60 -sec programmed total trial time had expired, a peck on the left key would result in the next trial's starting after 6 sec (prereinforcer delay) $+6 \mathrm{sec}$ (reinforcer access) $=12 \mathrm{sec}$, while a peck on the right key would result in the next trial's starting after $0.1 \mathrm{sec}$ (prereinforcer delay) $+2 \mathrm{sec}$ (reinforcer access) $+9.9 \mathrm{sec}$ (postreinforcer delay) $=12 \mathrm{sec}$. In addition, to the extent that the pigeons were sensitive to postreinforcer delay (although they were probably fairly insensitive to this variable, given the results of Logue et al., 1985), this procedure should have biased the pigeons' responding toward self-control (left key pecks); with long response latencies, there was a postreinforcer delay only following impulsive choices (right key pecks).

For every group of 10 trials, the 5th trial was a no-choice trial for the right key and the 10th trial was a no-choice trial for the left key. The no-choice trials required the pigeons to respond on only the left (green) key or the right (red) key. Only that key was lit, and a peck to that key led to the same sequence of events as on a choice trial. Pecks on the other key had no consequences. The no-choice trials ensured that a pigeon was exposed to the contingencies for pecks on both keys, regardless of the pigeon's preference.

There were 4 conditions (see Table 1). For Condition 1, each of the 4 pigeons was maintained at $80 \%$ of its free-feeding weight and participated in 15 23-h sessions, with 1 session every 4 th day (an open-economy procedure). For Condition 2, sessions were conducted similarly to those in Condition 1; however, the pigeons had ad-lib access to food in their home cages. Condition 3 was similar to Condition 2, except that all 15 sessions for a particular pigeon were conducted together, with the pigeon leaving the experimental chamber for only $1 \mathrm{~h}$ per day while the pigeon was weighed, the chamber was cleaned, and the chamber's food and water were replenished (a closed-economy procedure). In Condition 4, the procedure for the first 5 sessions was identical to the procedure used in Condition 3. For the other 15 sessions, the programmed total trial time was changed to $300 \mathrm{sec}$ in order to make it difficult for the pigeons to obtain sufficient food if they were impulsive. However, the programming of postreinforcer delays was in all other ways identical to the programming in the previous conditions. In other words, if, as a result of a long-latency choice of the left key, a period of reinforcer access ended after $300 \mathrm{sec}$, the next trial started immediately; if, as a result of a long-latency choice of the right key, a period of reinforcer access ended after the $300 \mathrm{sec}$, the next trial started after a $9.9-\mathrm{sec}$ postreinforcer delay.

\section{RESULTS}

Figure 3 presents the proportion of total responses that are self-control responses [left/(left + right) responses] as a function of hour in the 12-h light period and in the 11-h dark period, separately for each condition. The values shown are means over the individual pigeons' data. Data for an individual pigeon were obtained by taking means over the last 5 sessions, separately for each pigeon and each condition. Note that the values never rise as high as .4; the pigeons were consistently impulsive. In addi-

\begin{tabular}{|c|c|c|c|c|c|c|}
\hline $\begin{array}{r}\text { TRIAL N } \\
\text { KEYLIGHTS } \\
\text { ON }\end{array}$ & $\begin{array}{l}\text { LATENCY } \\
\text { TO } \\
\text { PECK }\end{array}$ & PECK & $\begin{array}{l}\text { PRE- } \\
\text { REINFORCER } \\
\text { DELAY }\end{array}$ & $\begin{array}{l}\text { REINFORCER } \\
\text { ACCESS } \\
\text { PERIOD }\end{array}$ & $\begin{array}{l}\text { POST- } \\
\text { REINFORCER } \\
\text { PERIOD } \\
\text { DELAY }\end{array}$ & $\begin{array}{l}\text { TRIAL } \\
N+1 \\
\text { KEYLIGHTS } \\
\text { ON }\end{array}$ \\
\hline LEFT & $X_{s}$ & & $6 s$ & $6 s$ & $\begin{array}{c}\text { a) IF } x_{s} \leq 48 s \text { THEN } \\
48 s-X_{s} \\
\text { b) IF } x_{s}>48 s \text { THEN } \\
0.0 \mathrm{~s}\end{array}$ & \\
\hline RIGHT & Ys & & 0.15 & $2 s$ & $\begin{array}{c}\text { o) IF Ys } \leq 48 \mathrm{~s} \text { THEN } \\
57.9 \mathrm{~s}-Y_{\mathrm{s}} \\
\text { b) IF } Y_{\mathrm{s}}>48 \mathrm{~s} \text { THEN } \\
9.9 \mathrm{~s}\end{array}$ & \\
\hline
\end{tabular}

Figure 2. Diagram of the procedure for determining postreinforcer delays. Note that the 60-sec programmed total trial time used to construct this diagram and employed in Conditions 1-3 was changed to 300 sec for Condition 4 . 
Table 1

The Order of Conditions and the Number of Sessions for Each Condition

\begin{tabular}{ccccc}
\hline $\begin{array}{c}\text { Condition } \\
\text { Number }\end{array}$ & $\begin{array}{c}\text { Initial } \\
\text { Weight of } \\
\text { Subject }\end{array}$ & $\begin{array}{c}\text { Programmed } \\
\text { Total Trial } \\
\text { Time }(\mathrm{sec})\end{array}$ & $\begin{array}{c}\text { Sequence of } \\
\text { Sessions }\end{array}$ & $\begin{array}{c}\text { Number of } \\
\text { Sessions }\end{array}$ \\
\hline 1 & $80 \%$ & 60 & Alternating & 15 \\
2 & $100 \%$ & 60 & Alternating & 15 \\
3 & $100 \%$ & 60 & Consecutive & 15 \\
$4 \mathrm{a}$ & $100 \%$ & 60 & Consecutive & 5 \\
$4 \mathrm{~b}$ & $100 \%$ & 300 & Consecutive & 15 \\
\hline
\end{tabular}

Note-In each condition, left key pecks resulted in a 6-sec delay followed by 6 -sec access to grain, whereas right key pecks resulted in a 0.1 -sec delay followed by 2 -sec access to grain.

tion, the functions for the light and dark hours repeatedly overlap in all of the conditions. There does not appear to have been any significant effect of condition or of light versus dark on self-control.

In order to compare more specifically the effects on selfcontrol of the different conditions as well as of the light and dark periods, and to make the analysis more manageable, matched $t$ tests were used to make all possible comparisons between the first and last hours of the light and dark periods for each condition (Hours 1, 12, 13, and 23 from the 23-h session; see Table 2 for the individual proportions used in making these comparisons). For tests comparing data from Condition 4 with data from other conditions, Pigeon 37 was matched with Pigeon 42, because Pigeon 37's responding was more like that of Pigeon 42 than that of Pigeon 43 (both Pigeon 42 and Pigeon 43 died following Condition 3 ). These comparisons of data from Condition 4 with data from other conditions were more conservative than nonmatched $t$ tests, because there were 2 pigeons that participated in Condition 4 as well as in every other condition (Pigeons 40 and 41).

There were a total of 48 comparisons. Simply by chance, 2 or 3 of these should have been significant. However, none of the tests were significant. Consistent with the appearance of Figure 3 discussed above, none of the manipulations had any effect on self-control. The pigeons were impulsive in all situations.

Given that the pigeons were consistently impulsive in all of the conditions, including Condition 4 , one might expect their weights to have decreased significantly from the 6th to the 20th session in Condition 4 (the closedeconomy sessions in which the pigeons could obtain reinforcers at most only once every $5 \mathrm{~min}$, as opposed to once every minute in the 1 st to the 5 th session). Table 3 gives the ending weight proportion of the beginning weight for each pigeon and each condition (using Sessions 6 and 20 for Condition 4). Means for each condition are also shown. Using $t$ tests, these means are not significantly different from 1.0 for Condition 4 or the other conditions. Despite their impulsiveness, the pigeons were able to maintain their weights close to their ad-lib weights when reinforcers were restricted in Condition 4 , and the experimenters were successful at keeping the pigeons' weights at $80 \%$ of ad lib throughout Condition 1 .

The pigeons might have been able to maintain their weights in Condition 4, despite impulsiveness, by simply obtaining more of the available reinforcers. Figure 4 presents the proportion of the maximum number of possible responses that were actually made (actual responses/maximum possible responses) during each hour in the 12-h light period and in the 11-h dark period,

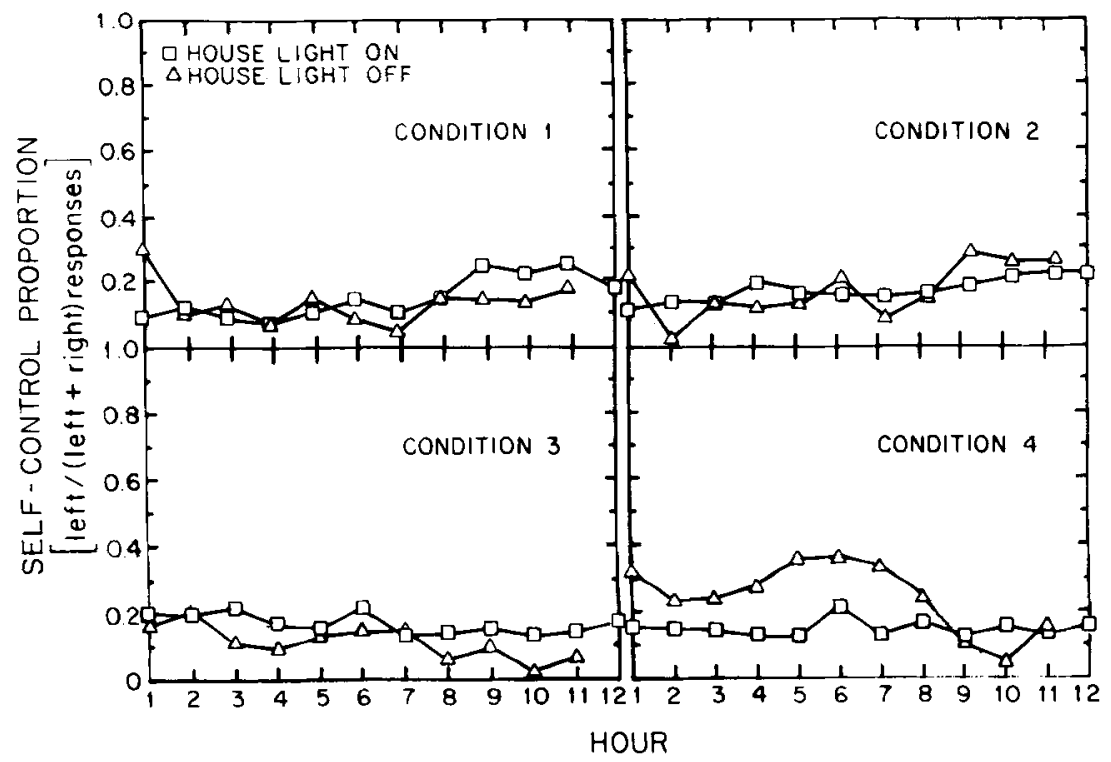

Figure 3. The proportion of responses that are self-control responses [left/(left + right) responses] as a function of hour in the 12-h light period and in the 11-h dark period, separately for each condition. The functions shown are means over all of the subjects in that condition. 
Table 2

Proportions of Total Responses That Are Self-Control Responses

[Left/(Left + Right) Responses] for Hours 1, 12, 13, and 23

for Each Pigeon and Condition

\begin{tabular}{|c|c|c|c|c|c|c|c|}
\hline \multirow[b]{2}{*}{ Hour } & \multicolumn{5}{|c|}{ Pigeon } & \multirow[b]{2}{*}{$M$} & \multirow[b]{2}{*}{$S E$} \\
\hline & 40 & 41 & 42 & 43 & 37 & & \\
\hline \multicolumn{8}{|c|}{ Condition 1} \\
\hline 1 & 0.14 & 0.02 & 0.05 & 0.16 & - & 0.09 & 0.03 \\
\hline 12 & 0.21 & 0.28 & 0.19 & 0.05 & - & 0.18 & 0.04 \\
\hline 13 & 0.24 & 0.28 & 0.48 & 0.24 & - & 0.31 & 0.05 \\
\hline 23 & 0.20 & 0.00 & 0.26 & 0.24 & - & 0.18 & 0.05 \\
\hline \multicolumn{8}{|c|}{ Condition 2} \\
\hline 1 & 0.06 & 0.06 & 0.25 & 0.10 & - & 0.12 & 0.04 \\
\hline 12 & 0.29 & 0.05 & 0.13 & 0.43 & - & 0.23 & 0.07 \\
\hline 13 & 0.19 & 0.34 & 0.00 & 0.37 & - & 0.22 & 0.07 \\
\hline 23 & 0.10 & 0.44 & 0.21 & 0.33 & - & 0.27 & 0.06 \\
\hline \multicolumn{8}{|c|}{ Condition 3} \\
\hline 1 & 0.31 & 0.18 & 0.21 & 0.12 & - & 0.20 & 0.04 \\
\hline 12 & 0.14 & 0.27 & 0.10 & 0.18 & - & 0.17 & 0.03 \\
\hline 13 & 0.37 & 0.03 & 0.00 & 0.26 & - & 0.17 & 0.08 \\
\hline 23 & 0.07 & 0.00 & 0.00 & 0.20 & - & 0.07 & 0.04 \\
\hline \multicolumn{8}{|c|}{ Condition 4} \\
\hline 1 & 0.16 & 0.10 & - & - & 0.21 & 0.16 & 0.03 \\
\hline 12 & 0.17 & 0.12 & - & - & 0.19 & 0.16 & 0.02 \\
\hline 13 & 0.14 & 0.18 & - & - & 0.65 & 0.32 & 0.14 \\
\hline 23 & 0.30 & 0.17 & - & - & 0.00 & 0.16 & 0.07 \\
\hline
\end{tabular}

separately for each condition. As in Figure 3 , the values shown are means over the individual pigeons' data.

First note that Figure 4 appears to indicate a diurnal pattern of feeding in Conditions 1-3, because the functions that represent responding in the light period are consistently above the functions that represent responding in the dark period. In Condition 4 there is some overlap between the light- and dark-period functions. To further explore this issue, Table 4 presents the proportion of total responses made during the light period by each pigeon in each condition. Means for each condition are also shown. The means for every condition except Condition 4 were significantly $(p<.05)$ greater than .50 [Condition $1, t(3)=+5.91$; Condition $2, t(3)=+13.04$; Condition $3, t(3)=+5.03$ ]; the pigeons did indeed tend to respond more frequently during the light period in Conditions 1-3. Any differences in the proportions of total responses made during the light period between conditions were also assessed. None of these comparisons were significant, except that the proportion of total responses made in the light period was significantly higher in Condition 2 than in Condition $4[t(2)=+4.72, p<.05]$. Although the mean proportion for Condition 4 (.65) was lower than the mean proportions for any of the other conditions, only the comparison with Condition 2 was significant.

Figure 4 also shows that, with the exception of the first hour in Condition 1 (the only time during the experiment when the pigeons were at $80 \%$ of their free-feeding weights) and many of the hours in Condition 4 , none of the points are above .7. The pigeons missed many opportunities to obtain reinforcers during most of Condition 1 and during all of Conditions 2-3.

To further examine the effects of the different conditions as well as the effects of the light and dark periods on responding, just as for the proportion of total responses that were self-control responses, $t$ tests were used to perform all possible comparisons between the proportions of maximum possible responses that were actually made during the first and last hours of the light and dark periods

Table 3

The Ending Weight Proportion of the Beginning Weight for Each Condition and Each Pigeon

\begin{tabular}{cccccccc}
\hline & \multicolumn{7}{c}{ Pigeon } \\
\cline { 2 - 8 } Condition & 40 & 41 & 42 & 43 & 37 & $M$ & $S E$ \\
\hline 1 & 0.99 & 0.99 & 1.01 & 0.99 & - & 1.00 & 0.00 \\
2 & 1.11 & 1.11 & 0.98 & 1.07 & - & 1.07 & 0.03 \\
3 & 1.02 & 1.03 & 0.96 & 0.99 & - & 1.00 & 0.01 \\
4 & 1.04 & 0.94 & - & - & 1.05 & 1.01 & 0.03 \\
\hline
\end{tabular}




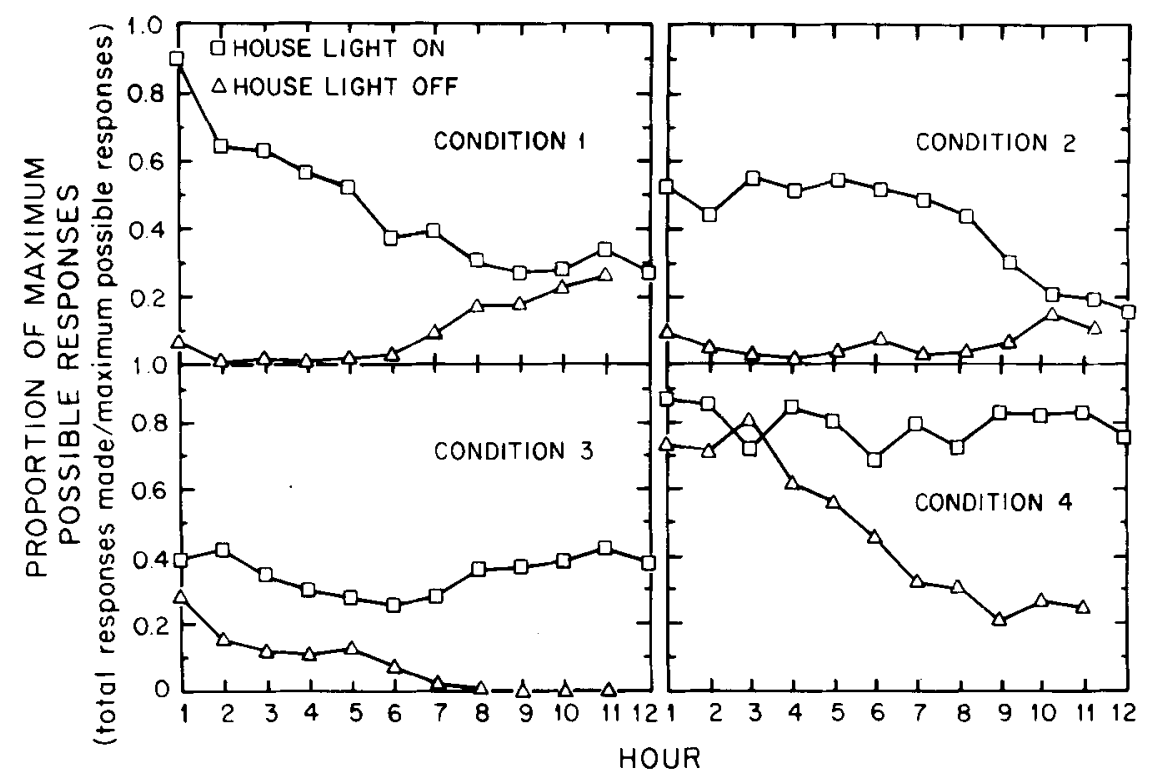

Figure 4. The proportion of maximum possible free-choice responses actually made (actual free-choice responses made/maximum possible free-choice responses) as a function of hour in the 12-h light period and in the 11-h dark period, separately for each condition. There were 48 maximum possible free-choice responses in each hour of Conditions 1-3 and 10 in each hour of Condition 4. The functions shown are means over all of the subjects in that condition.

for each condition (see Table 5 for the individual proportions used in making these comparisons). As in Table 2, there was a total of 48 comparisons; by chance, 2 or 3 of these should have been significant. However, in contrast to Table 2, which had no significant comparisons, 17 of the $t$ tests were significant (see Table 6). The most striking within-condition effects occurred for Conditions 1 and 2 , where there was a significant decrease in the proportions of maximum possible responses actually made from the first hour of the light period to the last light hour, to the first dark hour, and to the last dark hour. In addition, in Condition 1 the proportions decreased significantly from the last light hour to the first dark hour. In Condition 3, the proportions decreased significantly only from the first light hour to the last dark hour, and within Condition 4 there were no significant changes. With one exception, all of the significant findings between conditions involved proportions that were significantly less than in Condition 4. The exception involved significantly greater proportions in Condition 1 than in Condition 3 during the first light hour.

These findings, together with the findings discussed above, suggest that the pigeons were more likely to respond at the maximum possible rate in Condition 4 than in the other conditions, and that the pigeons tended to continue to respond in the dark period in that condition more than in the other conditions. This does not mean that the pigeons responded at a faster rate in Condition 4; it simply means that they were more likely to respond at the maximum possible rate (one response every $5 \mathrm{~min}$ ) in Condition 4 than in the other conditions (one response every minute). Table 7 shows the mean total number of responses made over the last 5 days in each condition by each pigeon. Condition means are also shown. Only the difference between the first and last conditions was significant $[t(2)=+33.67, p<.05]$. Thus, the pigeons actually responded somewhat more slowly in Condition 4 than in the other conditions, but they took greater advantage of the available opportunities to obtain reinforcers, well into the dark hours.

\section{DISCUSSION}

Whether or not the pigeons were food-deprived, whether or not there was more food available than they obtained, whether or not the economy was closed or open,

Table 4

The Proportion of Total Responses That Were Made in the Light (Hours 1-12) by Each Pigeon in Each Condition

\begin{tabular}{cccccccc}
\hline & \multicolumn{7}{c}{ Pigeon } \\
\cline { 2 - 8 } Condition & 40 & 41 & 42 & 43 & 37 & $M$ & $S E$ \\
\hline 1 & 0.77 & 0.99 & 0.78 & 0.76 & - & 0.83 & 0.05 \\
2 & 0.80 & 0.91 & 0.93 & 0.87 & - & 0.88 & 0.03 \\
3 & 0.81 & 0.69 & 1.00 & 0.98 & - & 0.87 & 0.06 \\
4 & 0.64 & 0.59 & - & - & 0.73 & 0.65 & 0.03 \\
\hline
\end{tabular}


Table 5

The Proportions of Maximum Possible Responses That Were Actually Made During Hours 1, 12, 13, and 23 by Each Pigeon in Each Condition

\begin{tabular}{|c|c|c|c|c|c|c|c|}
\hline \multirow[b]{2}{*}{ Hour } & \multicolumn{5}{|c|}{ Pigeon } & \multirow[b]{2}{*}{$M$} & \multirow[b]{2}{*}{$S E$} \\
\hline & 40 & 41 & 42 & 43 & 37 & & \\
\hline \multicolumn{8}{|c|}{ Condition 1} \\
\hline 1 & 0.87 & 1.00 & 1.00 & 0.74 & - & 0.90 & 0.05 \\
\hline 12 & 0.19 & 0.25 & 0.18 & 0.50 & - & 0.28 & 0.06 \\
\hline 13 & 0.05 & 0.05 & 0.05 & 0.11 & - & 0.06 & 0.01 \\
\hline 23 & 0.21 & 0.00 & 0.27 & 0.59 & - & 0.27 & 0.11 \\
\hline \multicolumn{8}{|c|}{ Condition 2} \\
\hline 1 & 0.41 & 0.47 & 0.40 & 0.80 & - & 0.52 & 0.08 \\
\hline 12 & 0.16 & 0.16 & 0.06 & 0.23 & - & 0.15 & 0.03 \\
\hline 13 & 0.22 & 0.08 & 0.00 & 0.07 & - & 0.09 & 0.04 \\
\hline 23 & 0.04 & 0.15 & 0.03 & 0.20 & - & 0.11 & 0.04 \\
\hline \multicolumn{8}{|c|}{ Condition 3} \\
\hline 1 & 0.38 & 0.47 & 0.22 & 0.51 & - & 0.39 & 0.06 \\
\hline 12 & 0.20 & 0.64 & 0.38 & 0.33 & - & 0.39 & 0.08 \\
\hline 13 & 0.33 & 0.71 & 0.00 & 0.08 & - & 0.28 & 0.14 \\
\hline 23 & 0.01 & 0.00 & 0.00 & 0.00 & - & 0.00 & 0.00 \\
\hline \multicolumn{8}{|c|}{ Condition 4} \\
\hline 1 & 0.70 & 1.00 & - & - & 0.94 & 0.88 & 0.08 \\
\hline 12 & 0.62 & 0.90 & - & - & 0.76 & 0.76 & 0.07 \\
\hline 13 & 0.78 & 0.66 & - & - & 0.78 & 0.74 & 0.03 \\
\hline 23 & 0.06 & 0.68 & - & - & 0.00 & 0.25 & 0.18 \\
\hline
\end{tabular}

whether or not sessions were conducted alternatively or consecutively, and despite the fact that the presentation of more than a single meal was studied, the pigeons were still impulsive. Figure 5 summarizes the consistent lack of self-control obtained in all of the conditions examined here. These findings are compatible with the argument that pigeons' impulsivity arises from their strong sensitivity to prereinforcer delay (for a summary, see Logue et al., 1985). These findings are not compatible with the argument that pigeons' impulsivity in previous laboratory experiments has been due to various unnatural characteristics of the laboratory situation (Collier, 1982, 1983). Even when these characteristics were eliminated here, the pigeons were still consistently impulsive.

These results may seem puzzling in light of previous research showing that nonhuman subjects can easily learn to wait for a preferred food or to obtain any food (see, e.g., Collier, 1982; Rashotte, O'Connell, \& Djuric, 1987). However, in Collier's experiments, the two alternatives between which the subjects were choosing differed in terms of the type of reinforcer to be received (e.g., carbohydrate vs. protein) and in terms of the work required to obtain each of the reinforcers (e.g., 5 leverpresses vs. 150 leverpresses). Rashotte et al. used an omission procedure in which there was only one alternative, and the pigeons obtained food by not pecking when a particular signal was present. In the present research, there were two alternatives which differed only in their delays and in the amount of the reinforcer to be received; there were no qualitative differences between the two alternatives. These three types of problems are not the same, and subjects may find the first two (Collier's and Rashotte et al.'s) easier than the third (the present research). In addition, the first two types of problems may be more representative of the choices that an animal must make in nature. If that is so, then the pigeons' impulsiveness in the present procedure may provide little information about pigeons' choice behavior in the real world. However, the pigeons' impulsiveness may still provide information about the cognitive capacities and limitations

Table 6

Significant $t$ Tests for the Proportions of Maximum Possible Responses

\begin{tabular}{cccccc}
\hline \multicolumn{5}{c}{$\begin{array}{c}\text { First Condition } \\
\text { and Hour Compared }\end{array}$} & \multicolumn{2}{c}{$\begin{array}{c}\text { Second Condition } \\
\text { and Hour Compared }\end{array}$} & \\
\cline { 1 - 2 } Condition & Hour & & Condition & Hour & $t(d f)$ \\
\hline 1 & 1 & 1 & 12 & $+4.84(3)$ \\
1 & 1 & 1 & 13 & $+11.20(3)$ \\
1 & 1 & 1 & 23 & $+3.62(3)$ \\
1 & 1 & 3 & 1 & $+4.52(3)$ \\
1 & 12 & 1 & 13 & $+3.67(3)$ \\
1 & 12 & 4 & 12 & $-8.35(2)$ \\
1 & 13 & 4 & 13 & $-16.98(2)$ \\
2 & 1 & 2 & 12 & $+5.08(3)$ \\
2 & 1 & 2 & 13 & $+3.82(3)$ \\
2 & 1 & 2 & 23 & $+6.64(3)$ \\
2 & 1 & 4 & 1 & $-5.60(2)$ \\
2 & 12 & 4 & 12 & $-7.13(2)$ \\
2 & 13 & 4 & 13 & $-9.23(2)$ \\
3 & 1 & 3 & 23 & $+6.08(3)$ \\
3 & 1 & 4 & 1 & $-4.47(2)$ \\
3 & 12 & 3 & 23 & $+4.07(3)$ \\
3 & 12 & 4 & 12 & $-7.36(2)$ \\
\hline
\end{tabular}

Note-Significance is defined as $p<.05$. 
Table 7

Mean Total Number of Responses Made by Each Pigeon in Each Condition

\begin{tabular}{cccccccc}
\hline & \multicolumn{7}{c}{ Pigeon } \\
\cline { 2 - 7 } Condition & 40 & 41 & 42 & 43 & 37 & $M$ & $S E$ \\
\hline 1 & 292.8 & 376.0 & 282.8 & 320.8 & - & 318.1 & 18.1 \\
2 & 167.4 & 323.0 & 158.2 & 410.6 & - & 264.8 & 53.3 \\
3 & 183.2 & 438.2 & 183.6 & 187.6 & - & 248.2 & 54.9 \\
4 & 126.6 & 192.0 & - & - & 104.8 & 141.1 & 21.4 \\
\hline
\end{tabular}

of pigeons-information that is indeed useful when trying to understand a species' ability to maximize reinforcement in its natural environment (Kamil \& Sargent, 1981; Lea, 1981).

The present results are also consistent with quantitative models of choice that have expressed choice as a function of prereinforcer delay independent of other parameters of reinforcement (see, e.g., Baum \& Rachlin, 1969; de Villiers, 1977; Fantino, 1977; Logue et al., 1984; Rodriguez \& Logue, 1986), and that have been found to hold even in 24-h and foraging procedures (Baum, 1972, 1974; Fantino \& Abarca, 1985). The results are inconsistent with models that ignore reinforcer delay and assume that all animals behave so as to maximize reinforcement over long intervals (see Mazur, 1981, for a description of this type of model).

Finally, the present results are characteristic of previous research with pigeons living in experimental chambers in that the pigeons demonstrated a diurnal pattern of feeding (Lucas, 1981; Zeigler, Green, \& Lehrer, 1971). The pigeons responded at the highest rates when they entered the chamber following several days in the home cage (Conditions 1 and 2). It should be noted that the pigeons disrupted their diurnal pattern when necessary to obtain sufficient food, an option not available in typical short-session self-control experiments. The pigeons did not adopt the other possible strategy: to show increased self-control (Condition 4). Apparently the motivation to respond in the light was not as strong as the sensitivity to prereinforcer delay. These results join others that have also found that food deprivation does not affect choice but does affect other aspects of responding (see, e.g., Logue \& Peña-Correal, 1985).

It is unclear why the pigeons' weights remained the same during Condition 4 despite the fact that they obtained fewer reinforcers in Condition 4. One possible explanation is that, in the deprivation situation of Condition 4, the pigeons' body temperatures (and therefore metabolic rates) were lower, thus conserving energy and enabling the pigeons to maintain their weights with lower food consumption. Such findings have been obtained with pigeons living in experimental chambers (Rashotte, 1985; Rashotte et al., 1986), and it has been well established in many species that food deprivation can result in lowered metabolic rate and thus minimization of weight loss (see Logue, 1986). However, the pigeons in Condition 4 made choices throughout most of the 23-h sessions; they were not inactive, which would have tended to keep their metabolic rates at normal levels. Perhaps the pigeons simply learned to consume more grain during the individual reinforcer access periods in Condition 4 (see Rashotte et al., 1987), thus keeping their total intake comparable to that in prior conditions.

In summary, the pigeons were impulsive even when they lived in the experimental chamber. They reacted to food deprivation or restricted access to food by obtaining a higher proportion of available reinforcers; they did not show more self-control. Increased motivation for food appears to affect pigeons' response rates but not their choices between larger, more delayed and smaller, less delayed reinforcers.

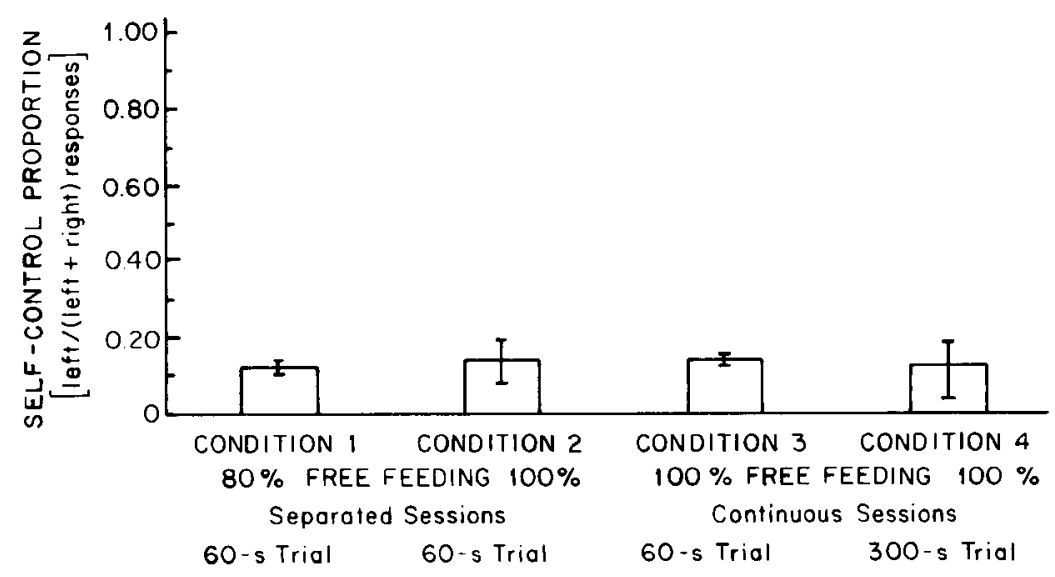

Figure 5. The proportion of responses that are self-control responses [left/(left + right) responses] over the entire session for each condition. The values shown are means over all of the subjects in that condition. The vertical bars indicate one standard error on either side of the mean. 


\section{REFERENCES}

Ainsuie, G. W. (1974). Impulse control in pigeons. Journal of the Experimental Analysis of Behavior, 21, 485-489.

Baum, W. M. (1972). Choice in a continuous procedure. Psychonomic Science, 28, 263-265.

Baum, W. M. (1974). Choice in free-ranging wild pigeons. Science, 185 , 78-79.

BaUm, W. M., \& RaChlin, H. (1969). Choice as time allocation. Journal of the Experimental Analysis of Behavior, 12, 861-874.

Bolles, R. C. (1985). The slaying of Goliath: What happened to rein forcement theory. In T. D. Johnston \& A. T. Pietrewicz (Eds.), Issues in the ecological study of learning (pp. 387-399). Hillsdale, $\mathrm{NJ}$ : Erlbaum.

Colluer, G. H. (1982). Determinants of choice. In D. J. Bernstein (Ed.), Nebraska Symposium on Motivation 1981 (pp. 69-127). Lincoln, NE University of Nebraska Press.

Collier, G. H. (1983). Life in a closed economy: The ecology of learning and motivation. In M. D. Zeiler \& P. Harzem (Eds.), Advances in anal ysis of behavior: Vol. 3. Biological factors in learning (pp. 223-274). New York: Wiley.

Collier, G., Hirsch, E., \& Kanarek, R. (1977). The operant revisited. In W. K. Honig \& J. E. R. Staddon (Eds.), Handbook of operant be havior (pp. 28-52). Englewood Cliffs, NJ: Prentice-Hall.

Collier, G. H., Johnson, D. F., Hill, W. L., \& Kaufman, L. W. (1986). The economics of the law of effect. Joumal of the Experimental Analysis of Behavior, 46, 113-136.

Commons, M. L., Herrnstein, R. J., \& Rachlin, H. (Eds.). (1982). Quantitative analyses of behavior: Vol. 2. Matching and maximizing accounts. Cambridge: Ballinger.

DE Viluiers, P. (1977). Choice in concurrent schedules and a quantitative formulation of the law of effect. In W. K. Honig \& J. E. R. Stad don (Eds.), Handbook of operant behavior (pp. 233-287). Englewood Cliffs, NJ: Prentice-Hall.

DUNN, R., \& FANTINo, E. (1982). Choice and the relative immediacy of reinforcement. Journal of the Experimental Analysis of Behavior 38, 321-326.

FANTINO, E. (1977). Conditioned reinforcement: Choice and information. In W. K. Honig \& J. E. R. Staddon (Eds.), Handbook of operant behavior (pp. 313-339). Englewood Cliffs, NJ: Prentice-Hall.

Fantino, E., \& ABARCA, N. (1985). Choice, optimal foraging, and the delay-reduction hypothesis. Behavioral \& Brain Sciences, 8, 315-330.

Grosch, J., \& NeURINGER, A. (1981). Self-control in pigeons under the Mischel paradigm. Journal of the Experimental Analysis of Behavior, 35, 3-21.

Hall-Johnson, E., \& Poling, A. (1984). Preference in pigeons given a choice between sequences of fixed-ratio schedules: Effects of ratio values and duration of food delivery. Joumal of the Experimental Analysis of Behavior, 42, 127-135.

HURSH, S. R. (1980). Economic concepts for the analysis of behavior. Journal of the Experimental Analysis of Behavior, 34, 219-238.

Hursh, S. R., \& Fantino, E. (1973). Relative delay of reinforcement and choice. Journal of the Experimental Analysis of Behavior, 19, 437-450.

Kamil, A. C., \& SARGent, T. D. (Eds.). (1981). Foraging behavior: Ecological, ethological, and psychological approaches. New York: Garland.

LEA, S. E. G. (1979). Foraging and reinforcement schedules in the pigeon: Optimal and non-optimal aspects of choice. Animal Behaviour, 27, 875-886.

LEA, S. E. G. (1981). Correlation and contiguity in foraging behaviour. In P. Harzem \& M. D. Zeiler (Eds.), Predictability, correlation, and contiguity (pp. 355-406). New York: Wiley.

LogAN, F. A. (1965). Decision making by rats: Delay versus amount of reward. Joumal of Comparative \& Physiological Psychology, 59, $1: 12$.

LoGuE, A. W. (1986). The psychology of eating and drinking. New York: Freeman.

LogUE, A. W., \& MAZUR, J. E. (1981). Maintenance of self-control acquired through a fading procedure: Follow-up on Mazur and Logue (1978). Behaviour Analysis Letters, 1, 131-137.

Logue, A. W., \& Peña-Correal, T. E. (1984). Responding during reinforcement delay in a self-control paradigm. Journal of the Experimental Analysis of Behavior, 41, 267-277.
Logue, A. W., \& Peña-Correal, T. E. (1985). The effect of food deprivation on self-control. Behavioral Processes, 10, 355-368.

Logue, A. W., Rodriguez, M. L., Peña-Correal, T. E., \& Mauro, B. C. (1984). Choice in a self-control paradigm: Quantification of experience-based differences. Journal of the Experimental Analysis of Behavior, 41, 53-67.

Logue, A. W., Smith, M. E., \& Rachlin, H. (1985). Sensitivity of pigeons to prereinforcer and postreinforcer delay. Animal Learning \& Behavior, 13, 181-186.

LuCAS, G. A. (1981). Some effects of reinforcer availability on the pigeon's responding in 24-hour sessions. Animal Learning \& Behavior, 9, 411-424.

MAzUR, J. E. (1981). Optimization theory fails to predict performance of pigeons in a two-response situation. Science, 214, 823-825.

Mazur, J. E., \& Logue, A. W. (1978). Choice in a "self-control" paradigm: Effects of a fading procedure. Journal of the Experimental Analysis of Behavior, 30, 11-17.

McDiarmid, C. G., \& Rilling, M. E. (1965). Reinforcement delay and reinforcement rate as determinants of schedule preference. Psychonomic Science, 2, 195-196.

MOORE, J. (1979). Choice and number of reinforcers. Journal of the $E x$ perimental Analysis of Behavior, 32, 51-63.

MOORE, J. (1982). Choice and multiple reinforcers. Journal of the Experimental Analysis of Behavior, 37, 115-122.

Peden, B. F., \& Timberlake, W. (1984). Effects of reward magnitude on key pecking and eating by pigeons in a closed economy. Psychological Record, 34, 397-415.

Rachlin, H., Battalio, R., Kagel, J., \& Green, L. (1981). Maximization theory in behavioral psychology. Behavioral \& Brain Sciences, 4, 371-417.

RACHLIN, H., \& GREEN, L. (1972). Commitment, choice and self-control Joumal of the Experimental Analysis of Behavior, 17, 15-22.

RashotTe, M. E. (1985, November). A hard day's night: Nocturnal hypothermia in response to high food costs in the $24 \mathrm{hr}$ closed economy. Paper presented at the meeting of the Psychonomic Society, Boston. Rashotte, M. E., \& O'ConNell, J. M. (1986). Pigeons' reactivity to food and to Pavlovian signals for food in a closed economy: Effects of feeding time and signal reliability. Journal of Experimental Psychology: Animal Behavior Processes, 12, 235-247.

Rashotte, M. E., O'Connell, J. M., \& Beidler, D. L. (1982). Associative influence on the foraging behavior of pigeons (Columba livia). Joumal of Experimental Psychology: Animal Behavior Processes, 8, 142-153.

Rashotte, M. E., O'Connell, J. M., \& DJuRic, V. J. (1987). Mechanisms of signal-controlled foraging behavior. In M. L. Commons, A. Kacelnik, \& S. J. Shettleworth (Eds.), Quantitative analyses of behavior: Vol. 6. Foraging (pp. 153-179). Hillsdale, NJ: Erlbaum.

Rashotte, M. E., Rautenberg, W., henderson, D., \& Ostheim, J. (1986, November). Thermal, metabolic and feeding reactions of pigeons when food is scarce. Paper presented at the meeting of the Psychonomic Society, New Orleans.

Rodriguez, M. L., \& LoGUE, A. W. (1986). Independence of the amount and delay ratios in the generalized matching law. Animal Leaming \& Behavior, 14, 29-37.

Shull, R. L., Spear, D. J., \& Bryson, A. E. (1981). Delay or rate of food delivery as a determiner of response rate. Journal of the $E x$ perimental Analysis of Behavior, 35, 129-143.

STADDON, J. E. R. (Ed.). (1980). Limits to action: The allocation of individual behavior. New York: Academic Press.

TIMBERLAKE, W. (1984). A temporal limit on the effect of future food on current performance in an analogue of foraging and welfare. Journal of the Experimental Analysis of Behavior, 41, 117-124.

Zeigler, H. P., Green, H. L., \& Lehrer, R. (1971). Patterns of feeding behavior in the pigeon. Journal of Comparative \& Physiological Psychology, 76, 468-477.

Zeigler, H. P., LevitT, P. W., \& Levine, R. R. (1980). Eating in the pigeon (Columba livia): Movement patterns, stereotypy, and stimulus control. Journal of Comparative \& Physiological Psychology, 94, 783-794.

(Manuscript received March 27, 1987; revision accepted for publication September 22, 1987.) 